\title{
INVESTIGASI PEMAHAMAN CALON GURU TENTANG KONSEP KALOR, KERJA, DAN PROSES-PROSES TERMODINAMIKA
}

\author{
Triwiyono dan Albert Lumbu \\ Fakultas Keguruan dan Ilmu Pendidikan \\ Universitas Cenderawasih \\ Email: y_triwiyono07@yahoo.co.id
}

\begin{abstract}
The purpose of this study are to describe the understanding of prospective teachers on the concepts of heat, work, and thermodynamic process and the difficulties they face in learning the concepts of thermodynamics. This research was conducted using qualitative method. Data were collected using a diagnostic test and interview. The subjects were students of physics education, University of Cendrawasih who had attended the lectures of thermodynamics, as many as 39 people. The results of this study indicate that student teachers do not understand the concept of heat, work, and thermodynamic process well. Students can analyze the problem and solve the majority of them (30\%). The settlement issue is not based on prior knowledge that already exists. Students have difficulty distinguishing the work done by the system or the environment. Students also have difficulty understanding the process in a diagram or change it in a different diagram.
\end{abstract}

Keywords: Students' Understanding, Concepts of Thermodynamics.

\section{Pendahuluan}

Lembaga pendidikan tenaga kependidikan (LPTK) ditugaskan untuk menyiapkan calon guru Indonesia. Guru yang dapat mendidik dan mengajar dengan baik, untuk menyiapkan sumber daya manusia (SDM) Indonesia yang berkualitas sesuai dengan tuntutan masyarakat yang terus berubah. Masyarakat menginginkan pendidikan yang bermutu dan menghasilkan lulusan yang siap kerja maupun siap melakukan studi lanjutan.

Untuk menghasilkan guru yang berkualitas, ada sejumlah persyaratan yang harus dipenuhi agar proses pendidikan calon guru berjalan dengan baik, sesuai dengan standar yang dipersyaratkan. Seleksi terhadap calon guru dilakukan secara selektif untuk menghasilkan calon guru yang kualitasnya baik. Sarana dan prasarana belajar di LPTK harus memenuhi standar minimal pendidikan calon guru. Didukung dengan kecukupan dosen yang bermutu, yang mampu menerjemahkan dan melaksanakan kurikulum perkuliahan dengan baik, serta dukungan masyarakat dan semua unsur yang terkait dengan proses penyiapan guru.

Menurut Prayitno (2007) lulusan LPTK yang akan menjadi guru harus menguasai ketiga komponen trilogi profesi yaitu: (1) komponen dasar keilmuan, (2) komponen substansi profesi, dan (3) komponen praktik profesi. Komponen dasar keilmuan yaitu substansi bidang ilmu yang akan menjadi mata ajar yang dibina selama menjadi guru mata pelajaran. Keilmuan tersebut harus dikuasai dengan baik oleh setiap calon guru. Komponen substansi profesi adalah ilmu keguruan yang antara lain berisi pedagogi, dedaktik dan metodik khusus mengajar, psikologi perkembangan dan sebagainya. Setiap calon guru harus menguasai keilmuan ini, agar dapat memberikan pelayanan mengajar dengan baik. Komponen pratik profesi yaitu berkaitan dengan performan mengajar didepan kelas.

Singh dan Rimoldini (2005) menyatakan dari penelitian tentang pemahaman konsep mahasiswa tentang konsep rotasi dan gerak menggelinding menyatakan bahwa pada umumnya mahasiswa kesulitan menerapkan prinsip kekekalan energi dan kesulitan memahami konsep kecepatan relatif. Temuan penelitian Swackhamar (1992), menunjukkan bahwa mahasiswa kesulitan dalam memahami hukum Newton III yang direpresntasikan dalam diagram untuk kasus benda jatuh bebas. Menurut laporan evaluasi kurikulum LPTK 1996/1997, penguasaan materi fisika calon guru, khususnya menyangkut fisika dasar dan fisika SMA, yang diukur pada mahasiswa LPTK dari delapan LPTK menunjukkan keadaan yang memprihatikan. Laporan ini menunjukkan bahwa 63\% mahasiswa termasuk dalam kategori non understanding, 34\% mahasiswa termasuk kategori partial understanding dan $2 \%$ mahasiswa termasuk complete understanding (Tim Basic Science LPTK, 1997).

Bertolak dari persoalan dalam bidang pendidikan tersebut, maka salah satu penelitian yang dikembangkan dalam pendidikan fisika adalah penyelidikan tentang pemahaman mahasiswa calon guru yang dikaitkan dengan berbagai konsep. Menurut Meltzer (2004), mahasiswa mempunyai pemahaman yang lemah pada konsep-konsep termodinamika. Penelitian tentang pemahaman konsep yang dikaitkan dengan berbagai variasi konsep adalah penting untuk mendukung pemilhan strategi pembelajaran yang dapat mengeliminasi berbagai masalah pembelajaran. Pada penelitian ini difokuskan pada pemahaman 
konsep mahasiswa calon guru tentang konsep kalor, kerja, dan proses-proses termodinamika. Alasan topik penelitian ini dipilih karena meteri termodinamika memiliki aplikasi yang luas dibidang ilmu lain dan memliki aplikasi yang tinggi di dalam kehidupan sehari-hari.

\section{Metode Penelitian}

Penelitian ini menggunakan metode kualitatif dengan pendekatan studi kasus. Pada penelitian ini, peneliti bertindak sebagai instrumen kunci untuk mengumpulkan data.pengumpulan data melalui tes diagnostik dan wawancara dengan responden penelitian ini dilaksanakan selama 10 bulan dari Februari - November 2015. Subyek penelitian adalah mahasiswa Program Studi Pendidikan Fisika yang menempuh kuliah termodinamika. Pemiliham subjek secara purposive. Subyek penelitian dipilih dengan mempertimbangkan kemampuan berkomunikasi agar proses pengungkapan berpikir dapat dilakukan dengan baik. Pada penelitian ini objek yang diteliti adalah pemahaman calon guru tentang konsep termodinamika.

Pengumpulan data dilakukan dengan menggunakan think alouds, yang meminta subyek penelitian untuk menyelesaikan masalah, sambil mengungkapkan yang sedang ia pikirkan. Think alouds dikembangkan oleh ahli psikologis kognitif dengan tujuan untuk mengungkap proses berpikir. Ketika seseorang memecahkan masalah, maka yang dipikirkan dapat direkam dan dianalisis untuk menentukan proses kognitif yang terkait dengan masalahnya. Dua hal penting dari metode thinks alouds (Olson, et.al, 1984) yaitu (1) siswa menulis dan menyatakan kesadaran berpikirnya ketika menyelesaikan masalah, (2) siswa harus melaporkan yang benar-benar mereka pikirkan saat ini dan bukan sekedar apa yang mereka ingat saat yang lalu.

Selanjutnya tahapan pengumpulan data dilakukan dengan langkah-langkah sebagai berikut (1) mahasiswa diberikan tugas berupa pertanyaan (tes diagnotis) yang harus dijawab dan diungkapkan secara langsung dengan suara keras, (2) peneliti merekam ungkapan verbal mahasiswa dengan bantuan audio dan video, (3) peneliti mengemukakan pertanyaan, hanya jika diperlukan untuk mendalami apa yang sedang dipikirkan oleh mahasiswa, (4) peneliti berperan mengendalikan dan memantau suasana agar koduksif untuk pengambilan data.

Dalam rangka mendalami masalah atau mengklarifikasi proses berpikir mahasiswa dilakukan wawancara. Dalam penelitian ini digunakan pedoman wawancara semi terstruktur, pertanyaan secara garis besar disusun terlebih dahulu, tetapi disesuaikan dengan keadaan dan ciri unik mahasiswa. Selama penelitian berlangsung peneliti meminimalkan intervensi ketika proses pengungkapan proses berpikir.

\section{HASIL DAN PEMBahasan}

Bentuk tes diagnotis berupa tes pilhan ganda beralasan. Tes diagnotis bagian I, disajikan pada gambar 1. Jawaban responden ditunjukkan pada Tabel 1.

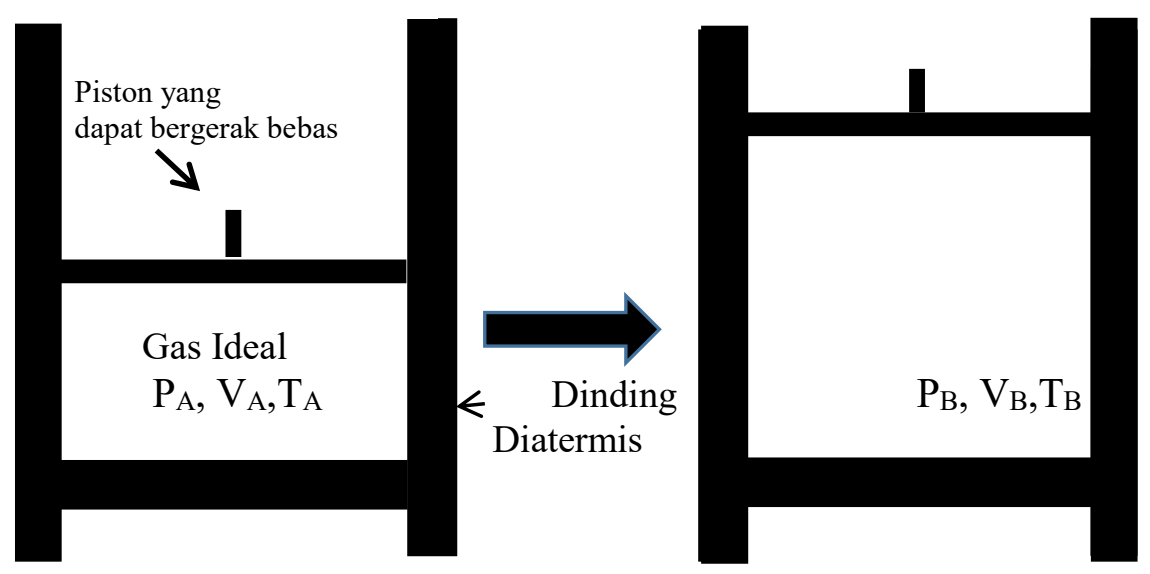

(A)

Gambar 1. Tes diagnotik bagian I

(B)

Gambar di atas menunjukkan suatu proses gas ideal yang terjadi pada tabung tertutup dari kondisi keadaan seperti pada gambar A, ke keadaan pada gambar $\mathrm{B}, \quad(\mathrm{P}=$ Tekanan, $\mathrm{V}=$ Volume, dan $\mathrm{T}=$ Temperatur).

\section{Pertanyaan:}

1. Selama proses berlangsung dari keadaan A ke keadaan $B$, dimana $T_{A} \neq T_{B}$, pernyataan berikut mana yang benar:

(a) Kerja positif, dikerjakan pada gas oleh lingkungan

(b) Kerja positif, dikerjakan oleh gas pada lingkungan

(c) Tidak ada kerja yang dikerjakan pada atau oleh gas 
Jelaskan alasan dari pada jawaban Anda!

2. Jika selama proses berlangsung $P_{A}=P_{B}$, gambarkan proses tersebut dalam diagram $\mathrm{P}-\mathrm{V}$ ?

Tes diagnotis pada bagian (1) ini, soal nomor 1 melihat bagaimana mahasiswa memahami fenomena kerja yang dilakukan oleh sistem pada lingkungan.
Diharapkan mahasiswa dapat mengaplikasikan formula $\mathrm{dW}=\mathrm{P} \mathrm{dV}$, dengan perjanjian kerja positif jika sistem melakukan usaha pada lingkungan dan sebaliknya. Sedangkan pada nomor (2) untuk melihat apakah mahasiswa memahami salah satu proses yang terjadi pada proses kuasi statis termodinamika.

Tabel 1. Data Hasil Tes Diagnotis Bagian I

\begin{tabular}{|c|c|c|c|c|c|c|c|}
\hline Soal & BB & BS & SS & BHB & BTA & $\begin{array}{l}\text { TDK } \\
\text { MJB } \\
\end{array}$ & JML \\
\hline \multicolumn{8}{|c|}{ Mahasiswa Calon Guru Angkatan 2013/2014 } \\
\hline 1 & $0 \%$ & $56 \%$ & $33 \%$ & $11 \%$ & $0 \%$ & $0 \%$ & $100 \%$ \\
\hline 2 & $94 \%$ & $0 \%$ & $6 \%$ & $0 \%$ & $0 \%$ & $0 \%$ & $100 \%$ \\
\hline \multicolumn{8}{|c|}{ Mahasiswa Calon Guru Angkatan 2012/2013 } \\
\hline 1 & $0 \%$ & $14 \%$ & $57 \%$ & $29 \%$ & $0 \%$ & $0 \%$ & $100 \%$ \\
\hline 2 & $81 \%$ & 0 & $19 \%$ & 0 & 0 & 0 & $100 \%$ \\
\hline
\end{tabular}

\section{Keterangan:}

BB: Jawaban benar, alasan benar; BS: Jawaban benar, alasan salah; SS: Jawaban salah, alasan salah; BHB: Jawaban benar, alasan hampir benar; BTA: Jawaban benar, tanpa alasan; TDK MJB: Tidak menjawab

Dari Tabel 1 menunjukkan bahwa mahasiswa calon guru yang menjawab benar untuk soal nomor 1 adalah $67 \%$ untuk angkatan 2013/2014 dan $43 \%$ untuk angkatan 2012/2013. Kemudian yang dapat memberikan jawaban benar dan alasan hampir benar (BHB) untuk mahasiswa angkatan 2013/2014 adalah $11 \%$, dan $29 \%$ untuk mahasiswa angkatan 2012/2013. Berikut adalah contoh alasan atau argumen yang dituliskan: 1) jika piston bergerak bebas, volume gas akan meningkat, molekul yang menumbuk piston memberikan gaya yang akan menyebabkan piston berpindah. Dengan demikian, molekul gas melakukan kerja posistif, 2) sistem menerima kalor dari lingkungan, energi dalam bertambah dan melakukan kerja.

Dari alasan tersebut mahasiswa menjawab dengan penalarannya yang hampir benar, tetapi belum Jawaban responden ditunjukkan pada tabel 2. memahami persoalan dengan baik. Alasan yang diharapkan adalah responden menggunakan pengetahuannya bahwa usaha adalah $\mathrm{dW}=\mathrm{P} d \mathrm{~V}$. Ketika terjadi perubahan volume positif, maka usaha positif dilakukan oleh sistem pada lingkungan. Jadi untuk persoalan nomor 1 ini, mahasiswa belum memahami secara baik konsep kerja atau usaha hidrostatik. Pada soal nomor 2, untuk kedua angkatan mahasiswa calon guru memberikan jawaban benar alasan benar (BB) yakni 94\% untuk angkatan 2013/2014 dan 81\% untuk angkatan 2012/2013. Soal nomor 2 ini tidak dituntut untuk memberikan alasan. Berikut adalah jawaban mahasiswa yang menjawab benar.

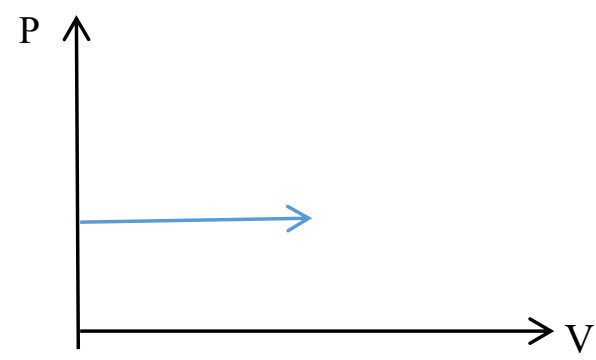

Tes diagnotis bagian II, diasajikan pada gambar 2 . 


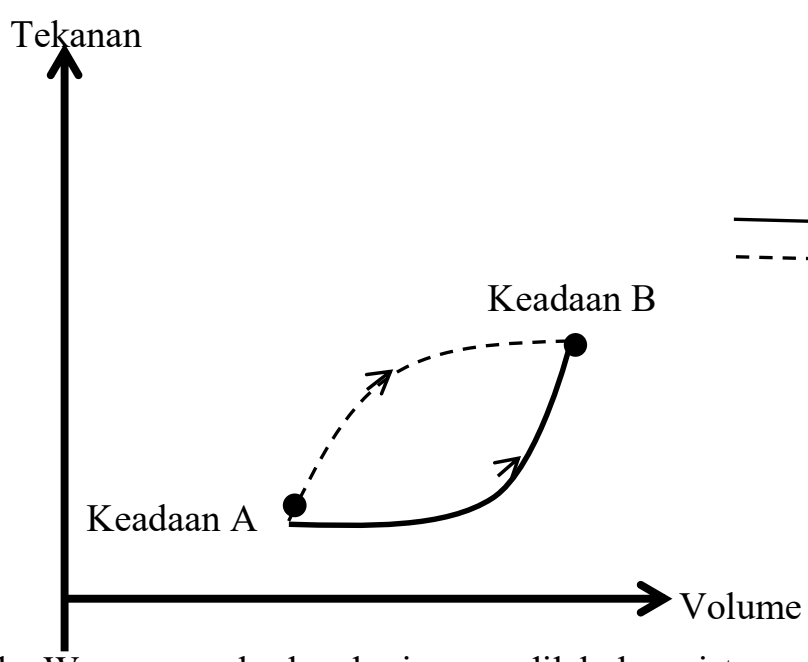

Jika W menggambarkan kerja yang dilakukan sistem selama proses berlangsung, dan Q menggambarkan kalor yang diserap oleh sistem selama proses berlangsung. Pernyataan yang benar berikut ini adalah:

1. (a) $\mathrm{W}$ proses $\# 1>\mathrm{W}$ proses $\# 2$.

(b) $\mathrm{W}$ proses $\# 1=\mathrm{W}$ proses $\# 2$.

(c) $\mathrm{W}$ proses $\# 1<\mathrm{W}$ proses $\# 2$

Jelaskan alasan dari pada jawaban Anda!

2. (a) Q proses \#1 > Q proses \#2.

(b) Q proses \#1 = Q proses \#2.

(c) Q proses \#1 $<$ Q proses \#2.

Jelaskan alasan dari pada jawaban Anda!

Gambar 2. Tes diagnotik bagian II

Tes diagnotis bagian 2 ini, untuk melihat pemahaman mahasiswa tentang kerja dan kalor yang bergantung pada proses (lintasan).

Tabel 2. Data Hasil Tes Diagnotis Bagian II

\begin{tabular}{cccccccc}
\hline Soal & BB & BS & SS & BHB & BTA & $\begin{array}{c}\text { TDK } \\
\text { MJB }\end{array}$ & JML \\
\hline \multicolumn{7}{c}{ Mahasiswa Calon Guru Angkatan } & $2013 / 2014$ \\
\hline 1 & $0 \%$ & $22 \%$ & $67 \%$ & $11 \%$ & $0 \%$ & $0 \%$ & $100 \%$ \\
2 & $0 \%$ & $22 \%$ & $67 \%$ & $0 \%$ & $0 \%$ & $11 \%$ & $100 \%$ \\
\hline \multicolumn{7}{c}{ Mahasiswa Calon Guru Angkatan } & $2012 / 2013$ \\
\hline & $33 \%$ & $10 \%$ & $43 \%$ & $14 \%$ & $0 \%$ & $0 \%$ & $100 \%$ \\
\hline
\end{tabular}

\section{Keterangan:}

BB: Jawaban benar, alasan benar; BS: Jawaban benar, alasan salah; SS: Jawaban salah, alasan salah; BHB: Jawaban benar, alasan hampir benar; BTA: Jawaban benar, tanpa alasan; TDK MJB: Tidak mahasiswa belum memahami secara baik tentang menjawab

Mahasiswa yang menjawab benar soal nomor 1 adalah 33\% untuk mahasiswa angkatan 2013/2014 dan mahasiswa angkatan 2012/2013 adalah 57\%. Dari data jawaban pada tabel 2 , menunjukkan bahwa

konsep usaha. Berikut ini adalah contoh variasi alasan 
mahasiswa yang menjawab benar dengan alasan salah (BS):

a. $\mathrm{W}=\mathrm{P} \Delta \mathrm{V}$, yang mana $\mathrm{W}$ berbanding lurus dengan tekanan dan volume, sehingga jika tekanan dan volume tinnggi, maka usaha yang dikerjakan juga besar.

b. Tekanan proses \#1, lebih kecil dari pada tekanan proses \#2

c. Usaha pada keadaan A, lebih kecil dari pada usaha keadaan B

Dari alasan responden, menunjukkan tidak ada alasan yang benar yakni (1) responden bernalar matematis semata, (2) fokus bahwa usaha bergantung semata-mata oleh tekanan, dan (3) usaha sebagai fungsi keadaan. Alasan yang diharapkan adalah bahwa besar usaha adalah besar luas daerah di bawah kurva, dan kerja bergantung pada proses (lintasan).

Pada soal nomor 2, mahasiswa angkatan $2013 / 2014$ menjawab benar $22 \%$ dan $86 \%$ mahasiswa angkatan 2012/2013. Persentase yang menjawab benar cukup tinggi, tetapi tidak ada yang memberikan argumen yang benar. Responden beralasan bahwa grafik pada soal menunjukkan grafik proses isotermis, sehingga dengan menerapkan hukum I termodinamika akan diperoleh $\mathrm{Q}=\mathrm{W}$, karena $\Delta \mathrm{U}=0$.

Tes diagnotis bagian III, diasajikan pada gambar 3 . Jawaban responden ditunjukkan pada tabel 3.

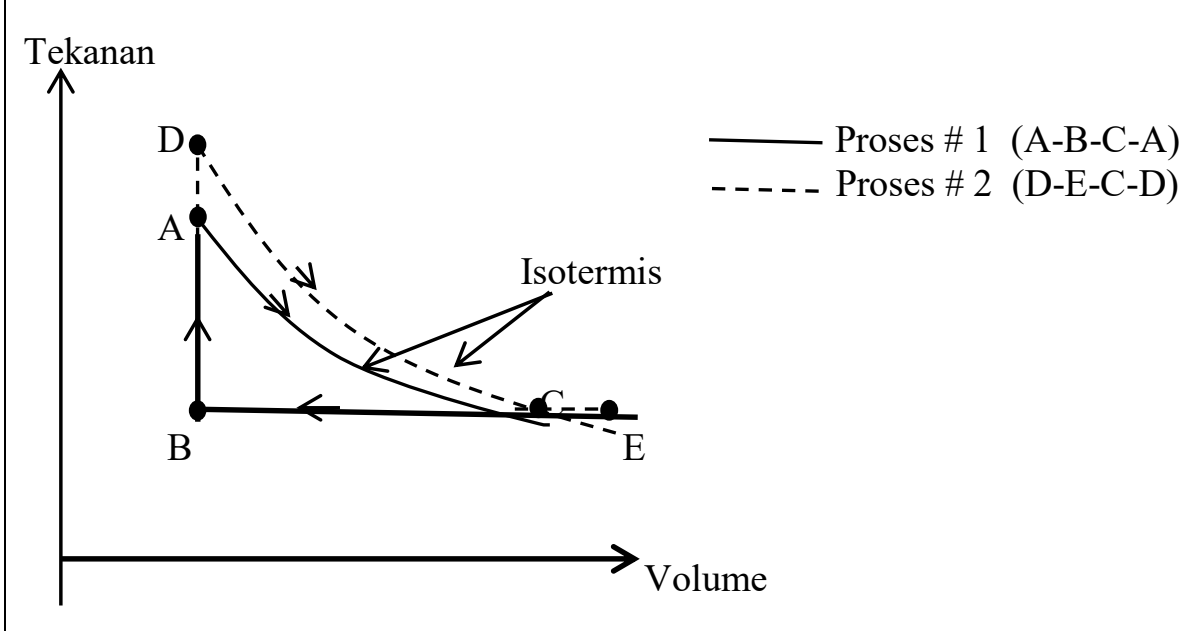

Suatu gas ideal menjalani proses seperti yang ditunjukkan pada gambar di atas.

Pertanyaan: Jika $\mathrm{W}_{\text {total }}$ menggambarkan usaha yang dilakukan sistem, dan $\mathrm{Q}_{\text {total }}$ menggambarkan kalor total yang diserap atau dilepaskan sistem, maka:

1. (a) $\mathrm{W}_{\text {total }}$ Proses $\# 1>\mathrm{W}_{\text {total }}$ Proses $\# 2$

(b) $\mathrm{W}_{\text {total }}$ Proses \#1 = $\mathrm{W}_{\text {total }}$ Proses \#2

(c) $\mathrm{W}_{\text {total }}$ Proses \#1 $<\mathrm{W}_{\text {total }}$ Proses \#2

Jelaskan alasan dari pada jawaban Anda!

2. (a) $\mathrm{Q}_{\text {total }}$ Proses $\# 1>\mathrm{Q}_{\text {total }}$ Proses \#2

(b) $\mathrm{Q}_{\text {total }}$ Proses \#1 = $\mathrm{Q}_{\text {total }}$ Proses \#2

(c) $\mathrm{Q}_{\text {total }}$ Proses \#1 $<\mathrm{Q}_{\text {total }}$ Proses \#2

Jelaskan alasan dari pada jawaban Anda!

Gambar 3. Tes diagnotik bagian III

Pada tes diagnotis bagian 3 ini, untuk melihat pemahaman mahasiswa tentang kerja dan kalor pada proses siklik termodinamika. 
Tabel 3. Data Hasil Tes Diagnotis Bagian III

\begin{tabular}{|c|c|c|c|c|c|c|c|}
\hline Soal & BB & BS & SS & BHB & BTA & $\begin{array}{l}\text { TDK } \\
\text { MJB }\end{array}$ & JML \\
\hline \multicolumn{8}{|c|}{ Mahasiswa Calon Guru Angkatan 2013/2014 } \\
\hline 1 & $11 \%$ & $22 \%$ & $28 \%$ & $22 \%$ & $11 \%$ & $6 \%$ & $100 \%$ \\
\hline 2 & $6 \%$ & $11 \%$ & $39 \%$ & $16 \%$ & $22 \%$ & $6 \%$ & $100 \%$ \\
\hline \multicolumn{8}{|c|}{ Mahasiswa Calon Guru Angkatan 2012/2013 } \\
\hline 1 & $33 \%$ & $5 \%$ & $29 \%$ & $33 \%$ & $0 \%$ & $0 \%$ & $100 \%$ \\
\hline 2 & $19 \%$ & $5 \%$ & $24 \%$ & $52 \%$ & $0 \%$ & $0 \%$ & $100 \%$ \\
\hline
\end{tabular}

\section{Keterangan:}

BB: Jawaban benar, alasan benar; BS: Jawaban benar, alasan salah; SS: Jawaban salah, alasan salah; BHB: Jawaban benar, alasan hampir benar; BTA: Jawaban benar, tanpa alasan; TDK MJB: Tidak menjawab.

Jawaban mahasiswa calon guru angkatan 2013/2014 persentase terbesar untuk soal nomor 1 dan nomor 2 adalah pada jawaban salah dengan alasan salah (SS). Hal itu berbeda dengan mahasiswa angkatan 2012/2013, 66\% menjawab benar dengan alasan benar untuk soal nomor 1 dan $71 \%$ untuk soal nomor 2 .

Setelah dilakukan analisis terhadap lembar jawab tes diagnotis, maka dikasanakan wawancara untuk menggali lebih mendalam tentang pemahaman konsep mahasiswa. Dari hasil wawancara dapat dipaparkan sebagai berikut.

\section{1) Konsep Kerja Hidrostatik}

Secara umum mahasiswa tidak memahami secara baik tentang konsep kerja hidrostatik.

a. Masih bingung kerja yang dilakukan sistem atau lingkungan yang melakukan kerja. Berkaitan dengan hal itu hanya $66 \%$ mahasiswa yang menjawab benar dengan alasan benar untuk soal bagian 1 tes diagnotis.

b. Masih bingung konsep kerja bergantung pada proses atau lintasan. Hasil tes diagnotis bagian 2, tidak ada mahasiswa yang menjawab benar dengan alasan benar.

Setelah dilakukan pengembangan pertanyaan seperti petikan wawancara berikut:

P: Coba perhatikan gambar grafik pada kedua proses ini

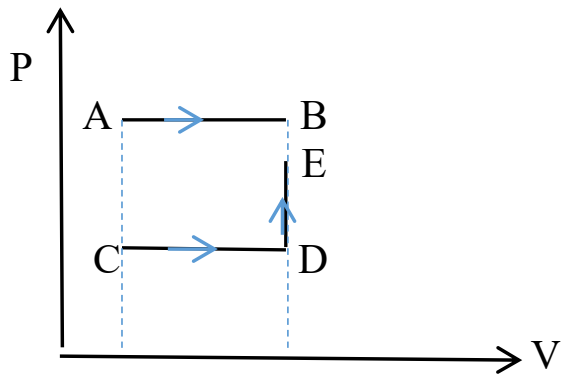

Manakah kerja (usaha) yang lebih besar dilakukan oleh sistem, proses $\mathrm{A}$ ke $\mathrm{B}$ atau proses $\mathrm{C}$ ke $\mathrm{D}$, lalu ke E?

R: Usaha C-D-E lebih besar dari pada usaha A-B

P: Alasanya?

R: Tekanan C ke D, lalu ke E bertambah besar.

Dari jawaban mahasiswa tersebut, menunjukkan bahwa, mahasiswa tidak memahami konsep kerja. Hanya 56\% mahasiswa yang menjawab benar bahwa usaha A-B lebih besar, dengan argumen yang benar dan hamper benar. Menjawab salah 11\% mahasiswa; menjawab bahwa usaha sama besar $11 \%$, dan $22 \%$ mahasiswa tidak menjawab. Pertanyaan kemudian diperluas lagi dengan membandingkan dua grafik dari suatu proses termodinamik sebagi berikut.

i) Kasus I

P: Perhatikan grafik

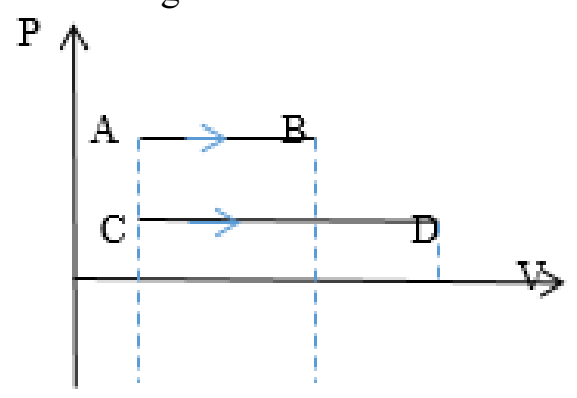

Manakah usaha yang lebih besar, proses A ke B atau proses $\mathrm{C}$ ke $\mathrm{D}$ ? 
ii) Kasus II

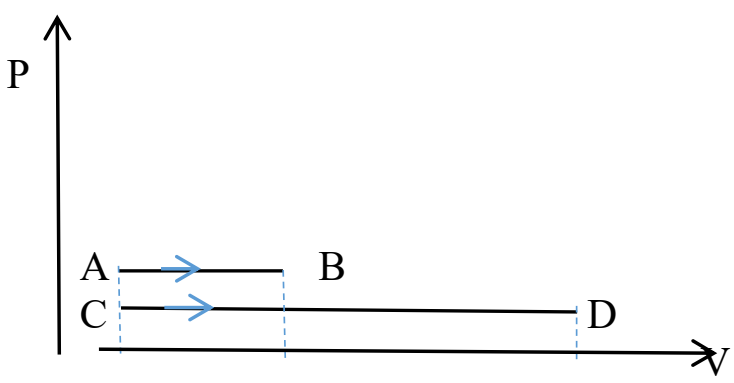

Manakah usaha yang lebih besar, proses A ke $\mathrm{B}$ atau proses $\mathrm{C}$ ke $\mathrm{D}$ ?
Berikut adalah jawaban mahasiswa: Untuk kasus I, 44\% menjawab kerja proses C-D lebih besar dari pada proses A-B dan Untuk kasus II, $33 \%$ menjawab kerja proses A-B lebih besar dari pada proses C-D.

2) Memahami Proses-proses Termodinamika Melalui Diagram

Hasil wawancara pemahaman terhadap proses-proses termodinamika disajikan pada tabel 4.

Tabel 4. Hasil wawancara pemahaman terhadap proses-proses termodinamika

\begin{tabular}{lccc}
\hline \multicolumn{1}{c}{ Uraian } & Paham & Paham Sebagian & Tidak Paham \\
\hline $\begin{array}{l}\text { Dapat menggambarkan proses } \\
\text { isothermal, isokorik, isobarik, dan } \\
\text { adiabatic dalam diagram P-V }\end{array}$ & $56 \%$ & $44 \%$ & $0 \%$ \\
$\begin{array}{l}\text { Dapat menggambarkan proses } \\
\text { isothermal, isokorik, isobarik, dan }\end{array}$ & $0 \%$ & $78 \%$ & $22 \%$ \\
$\begin{array}{l}\text { adiabatic dalam diagram P-T } \\
\begin{array}{l}\text { Dapat menggambarkan proses } \\
\text { isothermal, isokorik, isobarik, dan } \\
\text { adiabatic dalam diagram V-T }\end{array}\end{array}$ & $0 \%$ & $33 \%$ & $67 \%$ \\
\hline
\end{tabular}

Hasil wawancara terhadap pemahaman mahasiswa calon guru terhadap proses-proses termodinamikan yang direpresentasikan secara grafik menunjukkan bahwa sebagian besar mahasiswa hanya menguasai sebagian. Terlihat mahasiswa masih mengalami kesulitan dalam mentranformasi bentuk grafik dari bentuk diagram satu ke bentuk diagram yang lainnya.

\section{KESIMPULAN}

Hasil penelitian menunjukkan bahwa: 1) mahasiswa calon guru tentang konsep termodinamika masih memahami sebagian, 2) proses penalaran mahasiswa calon guru dalam menganilis soal-soal dan menyelesaikannya sebagian kecil (30\%). 3) Mahasiswa mengalami kesulitan membedakan kerja yang dilakukan oleh sistem atau lingkungan. Mahasiswa juga mengalami kesulitan memahami proses dalam diagram atau mengubahnya dalam diagram yang berbeda.

\section{REFERENSI}

[1] Hestenes. H, Wells. M, dan Swackhamer. G. (1992). Force Concept Inventory. The Physics Teacher. Vol 30, p. 141-158

[2] Melzer E. David. (2004). Investigation Of Students' Reasoning Regarding Heat, Work and The First Law of Thermodynamics in an Introductory Calculus-Based General. Physics Education Research. American Journal Physics, vol. 72 , no. 11

[3] Olson, G.M., Duffy, S.A., Mack, R.I. (1984). Thinkink-Out- Loud. Hillsdale, NJ: Erlbaum

[4] Prayitno. 20017. Trilogi Profesi Pendidik. FIP. UNP

[5] Rimoldini. L.G, dan Singh. C. (2005). Student Understanding of Rotational and Motion Concepts. Physical Review Special Topics. Physics Education Research 1010102.

[6] Tim Basic Science LPTK. 1997. Laporan Evaluasi Kurikulum LPTK Tahun 1996/1997 